Ekanayake, E.M.A.C., Shen, G.Q., Kumaraswamy, M.M. and Xue, J., 2021. Dynamic supply chain capability analysis of Hong Kong-Zhuhai-Macao bridge construction: A topic modeling approach. In: Sandanayake, Y.G., Gunatilake, S. and Waidyasekara, K.G.A.S. (eds). Proceedings of the $9^{\text {th }}$ World Construction Symposium, 9-10 July 2021, Sri Lanka. [Online]. pp. 268-279. DOI: https://doi.org/10.31705/WCS.2021.23. Available from: https://ciobwcs.com/papers/

\title{
DYNAMIC SUPPLY CHAIN CAPABILITY ANALYSIS OF HONG KONG-ZHUHAI- MACAO BRIDGE CONSTRUCTION: A TOPIC MODELING APPROACH
}

\author{
E.M.A.C. Ekanayake ${ }^{1}$, Geoffrey Qiping Shen ${ }^{2}$, Mohan M. Kumaraswamy ${ }^{3}$ and Jin \\ $\mathrm{Xue}^{4}$
}

\begin{abstract}
Prefabricated construction as a preferred construction approach instigated significant technological advancements in construction supply chains in Hong Kong (HK). The Hong Kong-Zhuhai-Macao Bridge (HZMB) was a milestone prefabricated construction project which was successfully constructed using these industrial advancements. However, the project itself was a great challenge as it was highly vulnerable to disruptions due to complex supply chain processes. In this regard, increased resilience could be the key to boosting project performance through enhanced Supply Chain Capabilities (SCCs), where identifying SCC dynamics becomes essential. Therefore, this study employed the Topic Over Time Modeling approach to detect critical SCCs using 1,748 unstructured official documents on the HZMB from 2003 to 2018, which spans the period from project design to handover. The popularity trend analysis of texts enabled identifying the six most critical capabilities associated with each construction phase of planning, construction and handover. Thereafter, an ex-post capability evaluation map was developed by considering the popularity trend of capabilities and their relevance to different project phases. Industry practitioners would benefit from prior knowledge of SCCs and their dynamic impact on each project phase to prioritize initiating them adequately and appropriately, targeting value-enhanced-resilient supply chains in exante decision-making of future prefabricated infrastructure development projects. Further, the text-mining research approach unveils to academia, an effective and novel mechanism to extract dynamic empirical clues from a large unstructured set of documents in construction SCC analysis research.
\end{abstract}

Keywords: Hong Kong-Zhuhai-Macao bridge; Prefabricated construction; Supply chain resilience; Supply chain vulnerabilities; Topic over time modeling.

\footnotetext{
${ }^{1}$ Department of Building and Real Estate, The Hong Kong Polytechnic University, Hong Kong, anushika.ce.ekanayakemudiyanselage@connect.polyu.hk

${ }^{2}$ Department of Building and Real Estate, The Hong Kong Polytechnic University, Hong Kong, geoffrey.shen@polyu.edu.hk

${ }^{3}$ Department of Civil Engineering, University of Hong Kong, Hong Kong, mohan @ hku.hk

${ }^{4}$ Department of Building and Real Estate, The Hong Kong Polytechnic University, Hong Kong, jin.xue@connect.polyu.hk
} 


\section{INTRODUCTION}

Prefabricated construction techniques have enabled hitherto unattained innovations in safe, clean, highly efficient and advanced construction methods in the Hong Kong (HK) construction industry. However, the inherent supply chain complexities and fragmentations call for resilient supply chains by developing Supply Chain Capabilities (SCCs) that can help deal with consequential disruptions and boost project performance (Ekanayake et al., 2021). The Hong Kong-Zhuhai-Macao Bridge (HZMB) is a milestone prefabricated infrastructure development project that recently raised the HK construction industry to new heights of international recognition. Significantly, the project received an award from the UK Institution of Civil Engineers for its achievements in project management and contribution to enhancing regional transportation networks. The HZMB being $55 \mathrm{~km}$ long, is the longest bridge-cum-tunnel sea crossing in the world ( $\mathrm{Li}, 2019)$.

The project was constructed in line with China's $13^{\text {th }}$ Five-Year Plan, which aimed to create an economic hub in the Greater Bay Area (Li, 2019). The bridge is located at the Pearl River entrance and connects three regions of Hong Kong, Zhuhai, and Macao under the political system entitled: 'One Country, Two Systems'. Considering the project scope, the design and construction of the HZMB included three navigation channel bridges, $22.9 \mathrm{~km}$ of marine viaducts, $6.7 \mathrm{~km}$ of immersed highway tunnel and two artificial islands (Lu, 2020). Figure 1 depicts the coverage of this mega construction development.

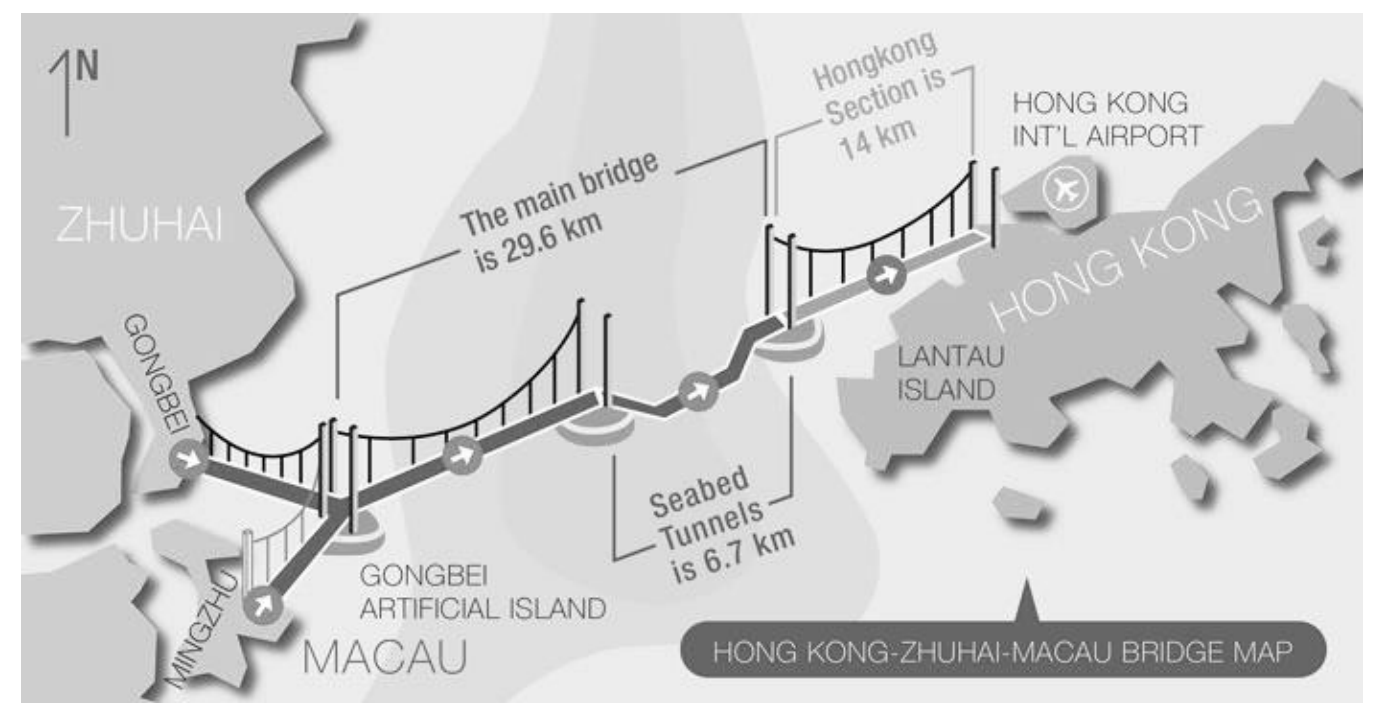

Figure 1: Coverage of the HZMB development (Source: www.ilikese.com, n.d.)

The project's specific location, challenging construction conditions, higher quality requirements, longer service life expected compared to the other similar projects (120 years) and significant safety concerns necessitated that it be developed on the basis of offsite factory-production, standardization and on-site assembly (Lu, 2020). As a result, the main bridge elements, including steel box girders, piers, pile caps, steel pylons and concrete-steel composite box-girders, were prefabricated in newly built prefabrication yards (Zeng et al., 2018; Zhou et al., 2018). The prefabricated components were transported through maritime routes using large pontoons and assembled using the horizontal piece-by-piece assembly method (Lu, 2020). With advanced prefabricated construction methods, the project could be completed safely, innovatively and economically in an environmentally friendly mode (Lu, 2020). 
However, these innovative construction methods, advanced technology and equipment injected a new set of challenges that increased project supply chain complexities and vulnerabilities (Hu et al., 2015). Manufacturing the prefabricated components required advanced technology and specific expensive equipment (Ming, 2017). As the components were heavy and bulky [i.e., 420,000 tons of box girders] (Lu, 2020), transportation and assembly became extremely challenging (Zhou et al., 2018). Also, the logistics phase was severely disturbed by the weather conditions, marine waves, marine traffic, aviation height restrictions and safety (Zhou et al., 2018). These added variables superimposed more challenges, which the project team had to cope carefully to ensure the success of this high-profile mega construction project.

In response, various capabilities were instilled in the supply chain process. These included supplier capacity development (Zeng et al., 2018), modular product design (Lu, 2020), more advanced technology (Ming, 2017), meticulous coordination and enhanced collaboration (Zhou et al., 2018), also deploying risk anticipation methods (Hu et al., 2015). All these innovations and commitments unsurprisingly helped the project to achieve improved quality and safety while shortening the construction time compared to traditional construction approaches (Lu, 2020). However, Li (2019) argued that the risk analysis, risk mitigation and prevention measures that were used, could not handle all the challenges, while specific risk management strategies seemed lacking. This led to the project overrunning its timeline and the revised budget of RMB 127 billion, exceeding the allocation of RMB 72.7 billion (Li, 2019). Therefore, the case of HZMB provides a valuable opportunity to learn useful lessons from both successes and failures in developing resilient prefabricated construction supply chains.

On the other hand, there is a rising demand for a comprehensive understanding of SCCs targeting resilient construction supply chains (Zainal and Ingirige, 2018), while it has become more significant in the prefabricated construction subdomain (Ekanayake et al., 2021). In response, Ekanayake et al. (2020) have identified the critical SCCs associated with prefabricated construction in HK through an expert opinion survey. Notably, the results of Ekanayake et al. (2020) were not tested using a more specific case study of an infrastructure development project. Also, the results were subjective and depended on respondents' quality (Yin, 2017). Further, it was based on static analysis; hence, it lacks the evidence to support the dynamics of SCCs throughout the project phases (Lin et al., 2018). These limitations could be successfully overcome through text mining and case study research (Xue et al., 2020). Topic modeling is a robust text-mining tool that detects the core commonalities among a pool of texts (Wang and McCallum, 2006). Among the topic modeling methods, Topic Over Time (TOT) modeling is considered to be more effective (Xue et al., 2020) as it explores both the content of core concepts and the dynamic concept patterns (Wang and McCallum, 2006).

After considering all these merits, TOT modeling is regarded as appropriate to analyze the dynamics of SCCs using the project documents of this HZMB project. Further, adhering to this method enabled objective case analysis using a large, quantitative, credible and empirical dataset of official documents related to the selected case. Therefore, this study aimed to develop an ex-post SCC evaluation map by introducing TOT modeling as a novel method for SCC analysis, using a large set of unstructured project documents of the HZMB project. As a result of the analysis, the critical SCCs and their annual trend could be explored under each project stage of planning, construction, and handover based on the project timeline. Then, the results were appropriately mapped 
against project phases, and the ex-post SCC evaluation map was developed. The developed map is proposed as an SCCs initiation guide for project professionals. Further, the identified failure points in the project helped strengthen the discussion by pointing to other necessary capabilities of prefabricated construction projects. The forthcoming sections of this paper present the research methods used, results and consequential discussions, practical research implications, and the conclusions, including research limitations and suggested ways forward.

\section{RESEARCH METHODS}

\subsection{Data Collection}

Figure 2 presents the research data collection and analysis methods used and the flow of this study. As in Figure 2, the relevant data (official documents related to the HZMB) were collected from the Hong Kong Legislative Council's official website. This website is publicly accessible. The data were considered highly reliable since the government maintained the data on this website. Further, the search terms "Hong Kong-Zhuhai-Macao Bridge" and "HZMB" were used to download all the relevant documents. As downloaded, there were 1748 official documents spanning the HZMB construction project period between 2003 to 2018, which spanned over the planning, construction and handover phases.

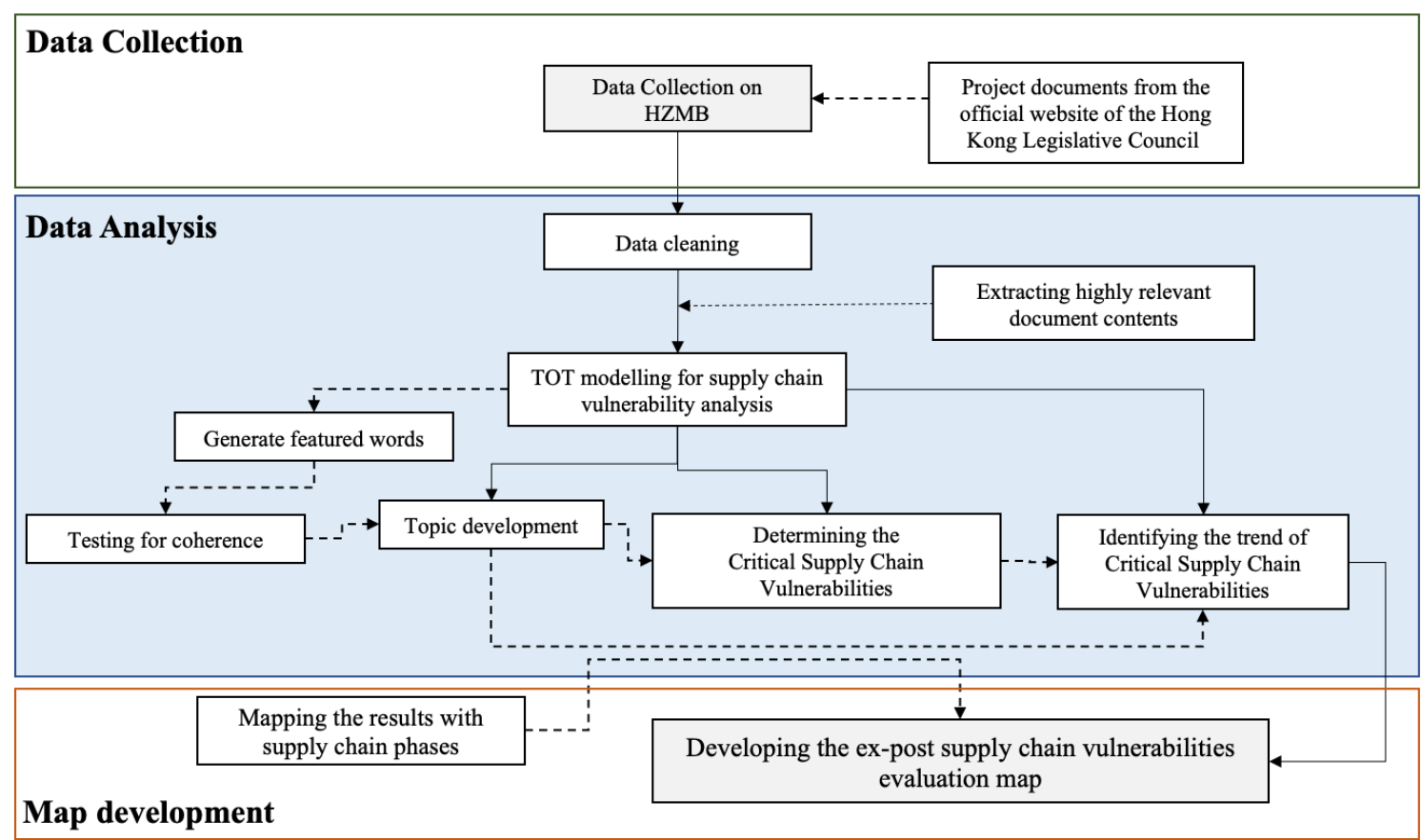

Figure 2: Research data collection, analysis and flow of this study

\subsection{Data AnALYSiS}

Data cleaning was first done by extracting the contents from the raw data files using keywords related to SCCs, prefabricated construction and the HZMB to begin the research data analysis. The keywords associated with SCCs were extracted from the study of Ekanayake et al. (2020), since those terms were already empirically verified for the prefabricated construction domain in HK. Therefore, the data extracted through the cleaning process can be considered to be highly relevant for this specific study. Then, the 
primary analysis was conducted using the TOT modeling technique. Compared to other topic modeling techniques such as Latent Dirichlet Allocation (LDA), PLSA and probabilistic theory, Topic Over Time (TOT) modeling is considered to be a more effective technique (Xue et al., 2020). This is because TOT captures the low-dimensional data structures, and also, TOT detects the structure's changes over time which is unavailable with the other topic modeling techniques (Wang and McCallum, 2006). Hence, TOT can facilitate more meaningful results considering both the content and the texts' timestamps (Wang and McCallum, 2006). All these advantages encouraged the authors to choose TOT modeling over other text mining techniques, to explore the texts and their distribution over timestamps associated with SCC analysis of the HZMB. Figure 3 further describes the TOT model used in Gibbs sampling (a commonly accepted model) (Wang and McCallum, 2006), which is also used in this current study.

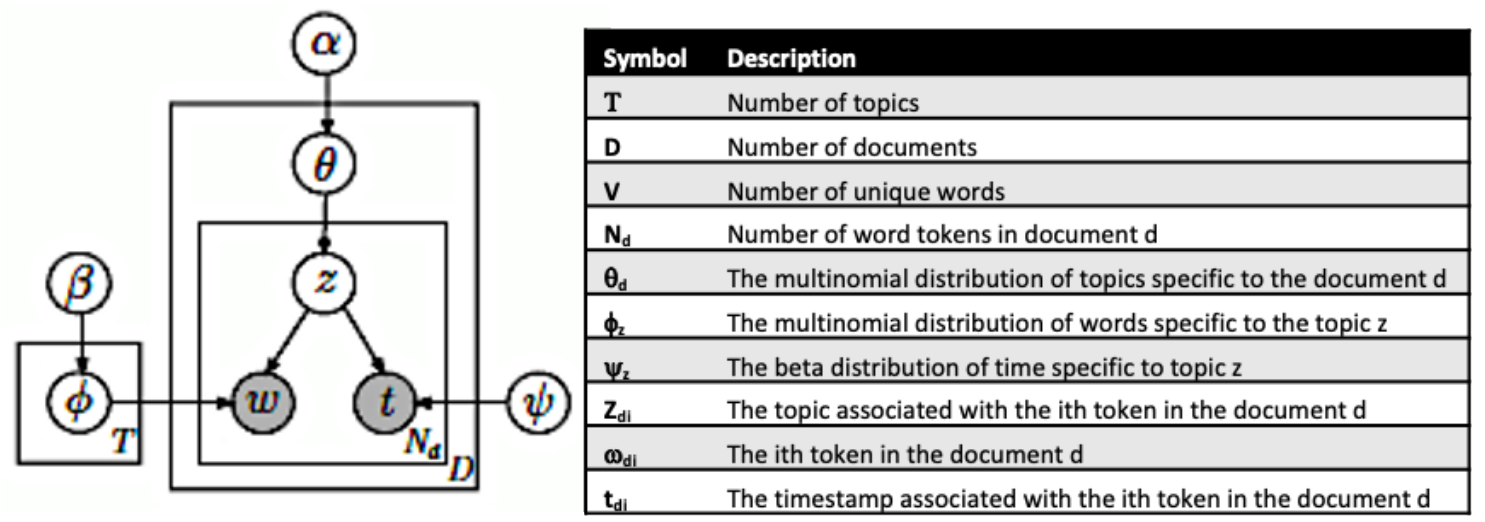

Figure 3: TOT model used in this study (Source: Wang and McCallum, 2006)

In TOT modeling, first, the timestamps were created for every word token. Then, following the study of Wang and McCallum (2006), each document's timestamp was counted by considering all the word timestamps in a document. The hyperparameters of $\alpha$ and $\beta$ were kept as $\alpha=50 / \mathrm{T}$ and $\beta=0.1$ (Xue et al., 2020) considering the model's simplicity (Wang and McCallum, 2006). Further, TF-IDF filtering was done prior to the modeling to enhance the texts' quality by removing frequent but meaningless texts. Finally, the model generated six SCC topics associated with the HZMB project, including 15 feature words with high relevant probabilities in each. Given the feature word list $V^{(z)}$, each topic's coherence [that measures the degree of logical consistency for text], $C\left(Z ; V^{(z)}\right)$ was calculated and tested using Equation 01, as suggested by Xue et al. (2020). In Equation 01, $\mathrm{D}(\mathrm{V})$ represents the document frequency; $\mathrm{D}\left(\mathrm{V}_{m}, \mathrm{~V}_{l}\right)$ represents the number of documents that contain both feature words of $\mathrm{V}_{m}, \mathrm{~V}_{l}$.

$$
C\left(Z ; V^{(z)}\right)=\sum_{m=2}^{15} \sum_{l=1}^{m-1} \log \frac{D\left(v_{m}^{(z)}, v_{l}^{(z)}\right)+1}{D\left(v_{l}^{(z)}\right)}
$$

\section{RESULTS AND DISCUSSION}

\subsection{CRITICAL SCCS ASSOCIATED WITH THE HZMB CONSTRUCTION AND THEIR TREND}

Table 1 presents the six topics identified through TOT modeling, feature words, topic concepts, and coherence values. The authors assigned the topic concepts, considering the common themes underlying the topics (Xue et al., 2020). These assigned topic concepts 
align with the associated feature words. Further, the TOT model was validated for its coherence and representativeness of the topics, following the method suggested by Mimno et al. (2011). Accordingly, the 6-topic TOT model of SCCs was regarded as the best valid model that interprets the project documents and evaluates critical SCCs. The developed six topic concepts are adaptability, anticipation, visibility, capacity, coordination and collaboration, and financial strength. These topics were considered as the critical SCCs employed during the HZMB construction. Figure 4 depicts the timestamps of these critical SCCs throughout the project duration (from 2003 to 2018). The planning phase was between 2003-2009, the construction phase was between 20102017, and the project was handed over in 2018.

Table 1: SCC topics developed through TOT modeling

\begin{tabular}{|c|c|c|c|}
\hline Topic & Concept & Feature words & $\begin{array}{c}\text { Average } \\
\text { coherence }\end{array}$ \\
\hline$\# 0$ & Adaptability & $\begin{array}{l}\text { technic; soon; improv; people; major; cost; commiss; } \\
\text { plan; associ; fund; implement; traffic; infrastructure; } \\
\text { transport; buffer }\end{array}$ & -49.0285 \\
\hline$\# 1$ & Anticipation & $\begin{array}{l}\text { transport; origin; direct; flow; connect; control; } \\
\text { enhance; link; crossboundari; manag; monitor; feasibl; } \\
\text { public; environment; urg }\end{array}$ & -57.9263 \\
\hline$\# 2$ & Visibility & $\begin{array}{l}\text { site; urg; build; marin; lead; } \\
\text { environmentalimpactassess; live; track; estim; cooper; } \\
\text { pearlriverdelta; develop; origin; safety; share }\end{array}$ & -73.9035 \\
\hline$\# 3$ & Capacity & $\begin{array}{l}\text { region; profession; meet; base; construct; conserve; } \\
\text { train; strateg; facil; option; econom; land; promot; line; } \\
\text { coordin }\end{array}$ & -66.4556 \\
\hline$\# 4$ & $\begin{array}{l}\text { Coordination } \\
\text { and } \\
\text { collaboration }\end{array}$ & $\begin{array}{l}\text { coordin; oper; consult; highway; hksar; mainland; } \\
\text { control; tunnel; pearlriverdelta; commun; progress; } \\
\text { opportun; region; mainbridg; peopl }\end{array}$ & -63.9743 \\
\hline \#5 & $\begin{array}{l}\text { Financial } \\
\text { strength }\end{array}$ & $\begin{array}{l}\text { competit; service; tuenmun; longterm; design; } \\
\text { increase; base; process; feasibl; improv; estim; fund; } \\
\text { flow; trade; demand }\end{array}$ & -66.7416 \\
\hline
\end{tabular}

Adaptability [\#0] was commonly applied in the project during the planning phase. This topic covers the ability to modify operations in response to disruptions. As the HZMB construction is new to the HK construction industry, proper 'technical ${ }^{51}$ decision-making to deliver the project was mandatory (Lu, 2020). Therefore, the project has considered several alternative technologies during project 'planning' and 'implementation'. New prefabrication factories were established with advanced technology separately for tunnel element production, steel girder production, pile cap, and pier production.

Further, automated production lines, innovative connections between prefabricated segments, automatic cutting and bending methods utilizing robots were used ( $\mathrm{Lu}, 2020)$ to enhance adaptability. As another adaptability measure, European technology was injected by outsourcing and adapting for the bridge deck paving work, blasting and asphalting ( $\mathrm{Lu}, 2020)$. Indeed, especially produced pontoons were used to 'transport' these heavy and lengthy segments (Hu et al., 2015). Innovative prefabricated roof

\footnotetext{
${ }^{5}$ These italic words are the feature words associated with each topic concept.
} 
modules were used to tackle airport height restrictions (Yau and Lok-kei, 2018). Building Information Modeling (BIM) based reporting tools were used throughout the project to enhance adaptability (Zhou et al., 2018). Besides, simulation studies were undertaken to properly 'plan' the project as most of the technology and approaches used were new (Hu et al., 2015). Also, the schedules were developed by accommodating reasonable time 'buffers'. Further, considering that the site is located in the white Dolphin protection zone (Li, 2019), the water breakers were designed to be environment friendly.

Topic \#0

Topic \#1

Topic \#2

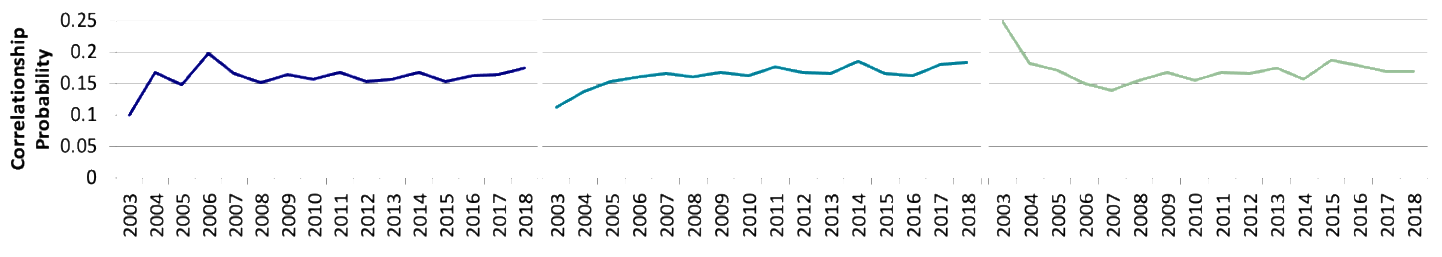

Topic \#3

Topic \#4

Topic \#5

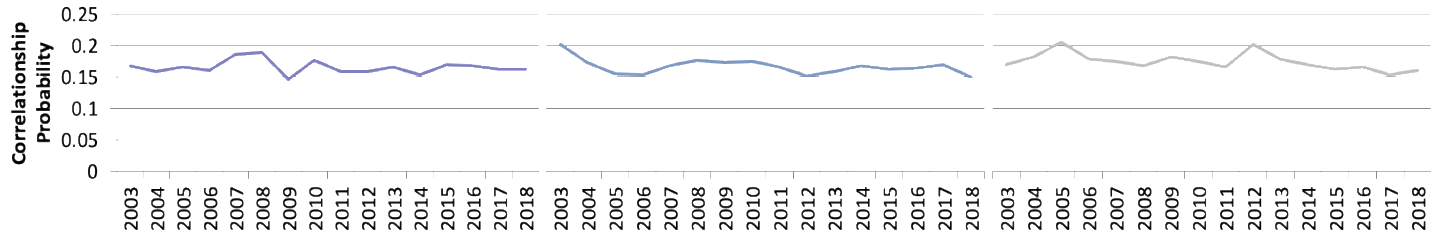

Figure 4: Topic trends developed through TOT modeling

Anticipation [\#2] was also necessitated as inherent disruptions surrounded the project due to its challenging location. 'Controlling' the prefabricated components during towing and installing was extremely difficult owing to high waves, strong currents and fickle weather. Hence, several observation stations were established, and frequent 'monitoring' and predicting of hydraulic and hydrographic information were needed all the time (Hu et al., 2015). Additionally, weather forecasting, and 'direction' and velocity 'monitoring' of wind and 'flow' were deployed frequently to ensure smooth operation plans ( $\mathrm{Hu}$ et al., 2015). Further, risk prediction and mitigation through Monte-Carlo simulations were initiated as an anticipation measure (Li, 2019).

Visibility [\#2] refers to having up-to-date knowledge of the 'site' operations. As shown in Figure 4, the highest visibility was in the planning phase as all the project professionals were linked with the BIM planning platform. Hence, information 'sharing' was up to date (Lu, 2020). More importantly, temporary governmental committees involving the central government and three local governments were established to enhance 'cooperation' and cross-function integration at various locations (Hu et al., 2018). The 'developed' RFID and BIM integrated systems facilitated real-time data' tracking' and tracing while enabling risk control (Zhou et al., 2018). Moreover, enhanced visibility could mitigate the vulnerabilities due to 'safety' hazards during transportation and assembly with the use of early prediction and warning systems (Zhou et al., 2018).

Capacity [\#3] development was another great challenge that the project team undertook. Capacity should be available to undertake continuous project operation throughout the project duration, as seen in Figure 4. First, the project employed a responsible 'professional' team, qualified contractors and suppliers throughout the supply chain (Zeng et al., 2018). Second, alternative production 'options' and 'strategies' were utilized in three newly constructed factories to 'meet' the project demand (Lu, 2020). Third, the 
outsourcing of special equipment and machinery was considered in manufacturing and assembly (Ming, 2017). Fourth, novel transportation methods were employed to avoid maritime traffic problems and safety hazards (Lu, 2020). Fifth, the horizontal piece by piece assembly method using floating cranes was deployed by mapping the assembly 'capacity' (Lu, 2020). Sixth, the HZMB authority spent much time and money to improve the suppliers' production 'capacities' and quality through technology support programs, 'training', and by allowing preferential prices (Zeng et al., 2018). Last, an independent and capable consultant group was hired for quality inspection (Zeng et al., 2018).

Collaboration and 'coordination' [\#4] are essential in prefabricated construction to avoid supply chain fragmentation issues (Ekanayake et al., 2020). Therefore, the HZMB has maintained this capability throughout the project span by enabling better 'communication' among the 'professionals'. All the project information were updated to the BIM-based data center, and collaborative decision making was achieved (Zhou et al., 2018). The data relating to the logistics and assembly phases were acquired through global positioning systems, sensors, sonar systems, RFID, and weather systems and transmitted immediately to the data center; while real-time element and 'progress' monitoring system, command system and deep-water automatic element immersion and position adjustment system were used for enhanced data operability (Zhou et al., 2018). Besides, several decision support systems were built to facilitate the 'opportunity' of collaborative and timely decision making. The meteorological and hydrological forecasting system to manage transportation and assembly was also helpful in this regard (Hu et al., 2015).

Financial strength [\#5] is an important and commonly required capability in such a mega infrastructure development project. That is why the capability has marked two peaks in the planning ('design') and construction phases (refer Figure 4). The project authority had to spend substantially on supplier capacity development (Zeng et al., 2018). Manufacturing of the prefabricated components using advanced technology was costly. Further, outsourcing required special equipment and machinery, which were extremely expensive (Ming, 2017). The transportation of the prefabricated components due to the offsite construction required expensive methods (Lu, 2020). The assembly of those elements also required particular cranes and specific arrangements to accommodate these cranes, which was very costly (Lu, 2020). Therefore, supplementing and sustaining cash 'flow' with government 'funds' was highly necessitated in mega construction development projects. To compete with the market' competition', the contractors involved in such projects need to consider their 'long-term' capacity development (Zeng et al., 2018).

\subsection{The EX-Post SCCs Evaluation Map and its Practical IMPLICATIONS}

The ex-post SCCs evaluation map was developed by incorporating the TOT modeling results (refer Figure 5). In Figure 5, the supply chain capabilities were located in each construction phase considering their trend and application levels derived from Figure 4. The slanting (up/down) lines [in Figure 5] that link the three construction phases indicate the increasing / decreasing patterns of each capability over the project duration as derived from Figure 4: correlational probabilities. The outcomes depicted in this map provides a managerial guide to the industry professionals to initiate SCCs appropriately in prefabricated construction projects. Using this map, the industry practitioners would benefit from prior knowledge of supply chain capabilities which is critical for infrastructure mega construction projects. The visualized dynamic impact on each project 
phase provides directions to prioritize implementing the critical SCCs adequately through appropriate capability development. For instance, as depicted in Figure 5, 'visibility' was highly required in the planning and construction phases compared to the handover stage. However, all these implications were based on project successes.

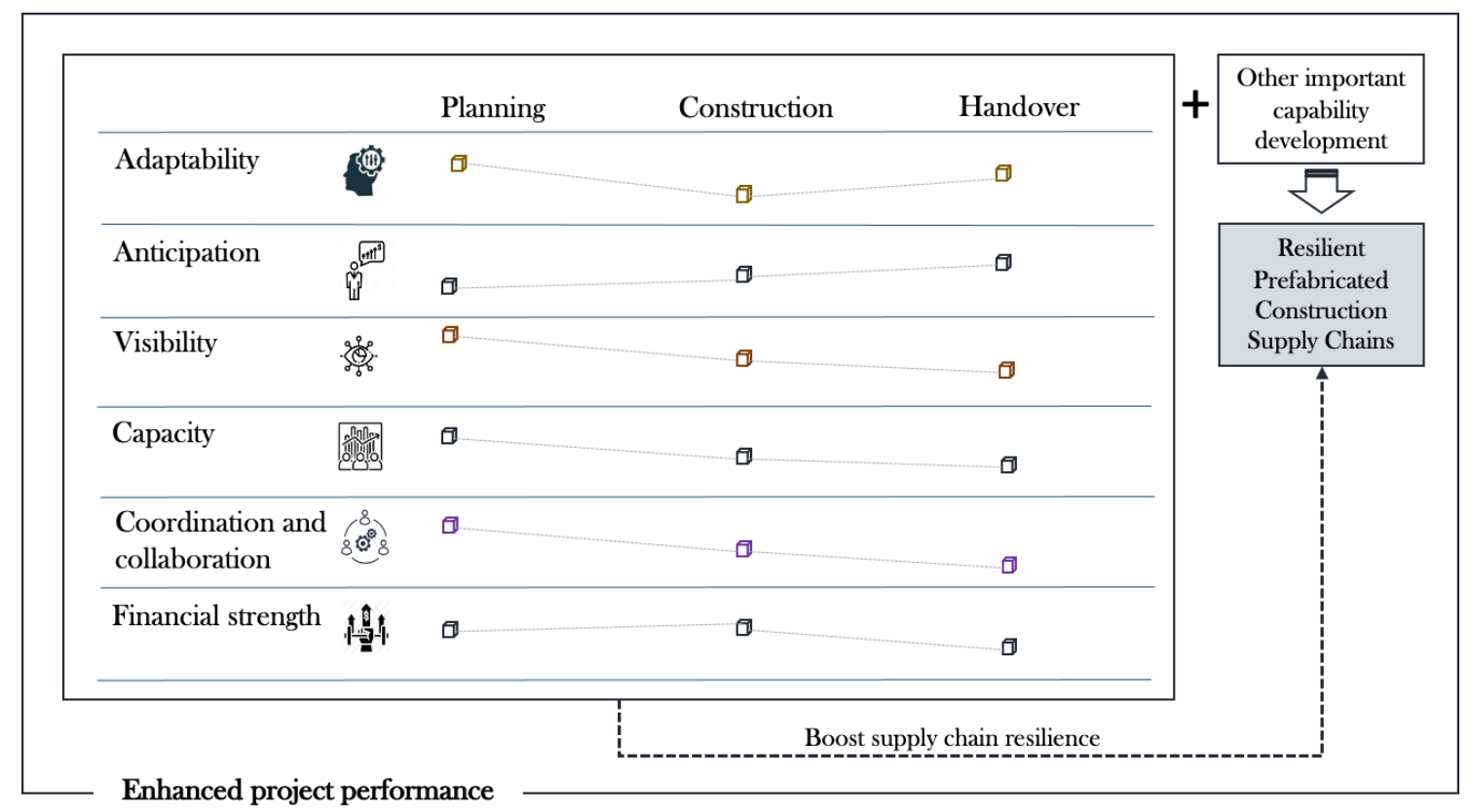

Figure 5: The ex-post SCC evaluation map

On the other hand, several failures should be indicated and analyzed to learn lessons from such a real-life case study. According to Li (2019), inadequate risk management is one of the limitations of this project. Also, transparent and decentralized decision-making must be adopted in other such projects to demarcate resilient supply chains. Other supply chain capabilities such as resourcefulness, flexibility, efficiency and dispersion would initiate more resilient aspects of prefabricated construction (Ekanayake et al., 2020). More importantly, vertically integrated supply chains may solve some problems associated with supply chain fragmentation. Flexible supply chains with alternative/multimodal transportation channels would be more resilient than in the HZMB.

According to $\mathrm{Hu}$ et al. (2015), the HZMB project has partially achieved a reasonable level of smart construction site management. Collaborative, transparent and quick decisionmaking can only be achieved through smart construction site management; hence, essential in supply chain resilience. Installation of 3D laser scanners and high-densityhigh-precision 3D point cloud data would enhance real-time tracking and tracing of the data (Zhou et al., 2018). The use of RFID, BIM, GIS and blockchain integrated platforms would boost collaboration, transparency, visibility, accountability and efficiency (Ekanayake et al., 2020). Therefore, all these other essential capabilities must be developed to establish resilient prefabricated supply chains in infrastructure development projects, as illustrated in Figure 5. Ultimately, project performance would be enhanced through all these SCC initiatives.

However, the identified capabilities should also be appropriately mapped with relevant supply chain vulnerabilities that any project faces. As all construction projects are unique, no other forthcoming project can be exactly like the one in this case study. Similarly, the 
supply chain configuration of each project cannot be identical. However, as in other case study research, the findings may be adapted or progressively generalized here too, by considering the prefabrication supply chain specific capabilities for similar megainfrastructure development projects. Moreover, although the present output is an ex-post decision-making map, improved ex-ante decision making is also enabled by this beneficial tool. Besides, the results are already validated through the findings of the current case-study. Therefore, the representative case choice, reliable information source, and the use of a large set of text documents in this study, add to the potential for progressive generalization.

More significantly, this is the first known study that enabled developing an SCC evaluation map based on the TOT modeling approach. Furthermore, this is the first known attempt to evaluate SCCs in infrastructure development projects focusing on increased resilience. Therefore, the novel research method employed, and the principal research outputs from this study significantly contribute to both construction and supply chain resilience research domains. The proposed research method could be initiated in other regions and/or projects where a large set of reliable project documents are available and also while considering the project-specific supply chain dynamics.

\section{CONCLUSIONS, LIMITATIONS AND WAYS FORWARD}

This study revealed the SCC dynamics underlying this high-profile HZMB megaprefabricated infrastructure development project through the Topic Over Time modeling approach. Six critical topics of capabilities, namely, adaptability, anticipation, visibility, capacity, collaboration and coordination, and financial strength, were identified and presented, based on the popularity trend analysis of texts. Finally, a decision-making map was developed by considering the popularity trend of capabilities and their relevance to different project phases to help visualize the dynamic capability impact on the HZMB construction. The developed map represents both theoretical and practical underpinnings of the dynamics and outcomes. Hence, industry practitioners would benefit from having prior knowledge of SCCs and the relative levels of the needs for them, as well as their dynamics in each project phase, enabling them to prioritize appropriate improvements, targeting value-enhanced-resilient supply chains in forthcoming prefabricated infrastructure development projects. Although an ex-post map is developed in this case, this methodology be effectively applied in robust ex-ante decision making.

This paper also discussed some limitations associated with the HZMB project due to its inadequate risk management strategies. Accordingly, the need for other important SCCs (flexibility, robustness, efficiency and dispersion) to achieve resilience was explicated and proposed. More significantly, the text-mining approach adopted in this study unveiled and offered a novel but verified SCC analysis approach. Being the first SCC analysis study, which used the TOT modeling, this study directs academia towards an effective mechanism to extract empirical clues from a large unstructured set of documents in the construction domain. As a way forward, the developed SCC evaluation map could be further expanded and strengthened in further research, using several other case studies and/or more empirical data. Since the supply chain capabilities are jurisdiction and industry-specific, the developed model can be extended towards other jurisdiction-based studies and other industry-based studies. Hence, this map could be beneficially generalized for different industrial contexts. Furthermore, the TOT model may be 
beneficially verified through a 'sentiment analysis' approach in future research. Finally, this study unveils useful implications for construction research and practice.

\section{ACKNOWLEDGEMENTS}

The authors wish to thank the Research Grants Council, the Innovation and Technology Commission, the Policy Innovation and Co-ordination Office of the Government of the Hong Kong Special Administrative Region, the Research Institute for Sustainable Urban Development, and the Hong Kong Polytechnic University for the funding support to the research which has contributed to the preparation of this paper.

\section{REFERENCES}

Ekanayake, E.M.A.C., Shen, G. and Kumaraswamy, M.M., 2020. Critical capabilities of improving supply chain resilience in industrialized construction in Hong Kong. Engineering, Construction and Architectural Management. (Ahead of print), Available at: DOI 10.1108/ECAM-05-2020-0295.

Ekanayake, E.M.A.C., Shen, G. and Kumaraswamy, M.M., 2021. Identifying supply chain capabilities of construction firms in industrialized construction. Production Planning and Control, 32(4), pp. 1-19.

Hong Kong-Zhuhai-Macao Bridge Map. (n.d.). https://www.ilikese.com/industry/traffic/ bridge/seabridge/hong-kong-zhuhai-macau-bridge/ [Accessed 10 March 2021].

Hu, Y., Le, Y., Gao, X., Li, Y. and Liu, M., 2018. Grasping institutional complexity in infrastructure megaprojects through the multi-level governance system: A case study of the Hong Kong-Zhuhai-Macao Bridge construction. Frontiers of Engineering Management, 5(1), pp. 52-63.

Hu, Z.N., Xie, Y.L. and Wang, J., 2015. Challenges and strategies involved in designing and constructing a $6 \mathrm{~km}$ immersed tunnel: A case study of the Hong Kong-Zhuhai-Macao Bridge. Tunnelling and underground space technology, 50(2015), pp. 171-177.

Li, T., 2019. Appraisal of decision-making on large-scale transportation infrastructure project: Case study of the Hongkong-Zhuhai-Macao Bridge in China. Thesis (MSc). Erasmus University Rotterdam.

Lin, H., Sui, Y., Ma, H., Wang, L. and Zeng, S., 2018. CEO narcissism, public concern, and megaproject social responsibility: Moderated mediating examination. Journal of Management in Engineering, 34(4), pp. 4018018:1-10.

Lu, H., 2020. Application of prefabrication and assembly to Hong Kong-Zhuhai-Macao Bridge. Frontiers Research of Architecture and Engineering, 3(2), pp. 6-12.

Mimno, D., Wallach, H., Talley, E., Leenders, M. and McCallum, A., 2011, July. Optimizing semantic coherence in topic models. In Proceedings of the 2011 conference on empirical methods in natural language processing, pp. 262-272.

Ming, L., 2017. Thinking and methods as to the risks of "Super Engineering" - Feedback to the HZMB Island-Tunnel Project [online]. Available from:

http://www.urmitongji.org.cn/en/research/constructional_engineering/2017070640.html [Accessed 10 March 2021].

Wang, X. and McCallum, A., 2006, August. Topics over time: a non-markov continuous-time model of topical trends. In: Eliassi-Rad, T. (ed). 12 th ACM SIGKDD international conference on Knowledge discovery and data mining, Philadelphia 20-23 August 2006. New York: Association for Computing Machinery, pp. 424-433.

Xue, J., Shen, G.Q., Li, Y., Wang, J. and Zafar, I., 2020. Dynamic stakeholder-associated topic modeling on public concerns in mega infrastructure projects: Case of Hong Kong-Zhuhai-Macao bridge. Journal of Management in Engineering, 36(6), pp. 4020078:1-16.

Yau, C. and Lok-kei, S., 2018. Safety concerns over artificial island at mega Hong Kong-Zhuhai-Macau bridge dismissed, South China Morning Post, 5 April [Online]. Available from: 
https://www.scmp.com/news/hong-kong/politics/article/2140330/safety-concerns-over-artificialisland-mega-hong-kong-zhuhai [Accessed 10 March 2021].

Yin, R.K., 2017. Case study research and applications: Design and methods. $6^{\text {th }}$ ed. California: Sage publications.

Zainal, N.A. and Ingirige, B., 2018. The dynamics of vulnerabilities and capabilities in improving resilience within Malaysian construction supply chain. Construction Innovation, 18(4), pp. 412-432.

Zeng, W., Zhang, J., Wang, H. and Zhou, H., 2018. Supplier development and its incentives in infrastructure mega-projects: A case study on Hong Kong-Zhuhai-Macao Bridge project. Frontiers of Engineering Management, 5(1), pp. 88-97.

Zhou, H., Wang, H. and Zeng, W., 2018. Smart construction site in mega construction projects: A case study on island tunnelling project of Hong Kong-Zhuhai-Macao bridge. Frontiers of Engineering Management, 5(1), pp. 78-87. 